\title{
LECTURE
}

\section{Laparoscopic Burch Procedure for Stress Urinary Incontinence: The Carter Modification}

\author{
James E Carter \\ Advanced Surgical Education Associates, Women's Health Center of South Orange County, Inc., Mission Viejo, \\ CA, USA
}

(Received for publication on June 13, 1995)

\begin{abstract}
Bladder neck suspension is now possible under laparoscopic control. The advantages of laparoscopy now apply to laparoscopic colposuspension. The technique described in this paper simplifies the laparoscopic Burch procedure by utilizing the harmonic scalpel for dissection of space of Retzius in a sharp and blunt fashion, providing for a bloodless dissection of the space, suturing of the perivaginal tissue avoiding penetration of the vaginal mucosa, placing the Stamey needle through a small skin incision, allowing for a variation in the shape of the pelvic bone so that the dissection of Cooper's ligament is performed in a very atraumatic fashion, extracorporeal knotting of the suture for ease of fixation of the perivaginal fascia to the Cooper's ligament and stapling of the peritoneal surface for reclosure of the space. With the adoption of this technique, the procedure of laparoscopic bladder suspension can be performed in most cases in approximately 1 hour of surgical time. The results are very encouraging, and the procedure as described in fact does not differ from the classical Burch procedure in any significant detail. Therefore, the long-term results are expected to be similar to those obtained by the standard Burch approach. No failures have thus far occurred in $\mathbf{5 0}$ patients over two years follow up. One patient did require urinary drainage through the suprapubic catheter for a period of one week prior to ability to void spontaneously. (Keio J Med 45 (3): 168-171, September 1996)
\end{abstract}

Key words: urinary stress incontinence, laparoscopy, retropubic suspension

\section{Introduction}

The Burch colposuspension for genuine stress urinary incontinence results in an objective incontinence cure rate ranging from 67 to over $95 \% .^{1-3} \mathrm{~A}$ technique of laparoscopic colposuspension identical to the procedure described by $\mathrm{Kranz}^{4}$ was described by Vancaille. ${ }^{5}$ The technique describe in this article follows the Burch approach of attachment to the Cooper's ligament using the Stamey needle to dissect the Cooper's ligament free of the periosteum and allowing the passage of the suspension suture around the Cooper's ligament for secure suspension.

\section{Material and Methods}

Patients were placed in the dorsal lithotomy position for laparoscopic-assisted vaginal hysterectomy which was accomplished in the standard manner as described by Carter and Bailey (Fig 1). ${ }^{6}$

Following the completion of the laparoscopic-assisted vaginal hysterectomy, the laparoscopic Burch procedure is initiated. The bladder is distended with $350 \mathrm{cc}$ of normal saline with methylene blue dye. The peritoneal surface overlaying the bladder at the cephalad border is opened with the use of the harmonic scalpel (Ultracision Inc., Smithfield, RI, USA). The space of Retzius is dissected with the use of the harmonic scalpel which provided for a nearly bloodless dissection in this somewhat vascular space (Fig 2). The perivaginal space is identified by sharp and blunt dissection with the placement of finger pressure into the vagina, allowing the perivaginal fascia to be easily palpated and located. The Cooper's ligament is identified by blunt and sharp dis-

Presented at the 921st Meeting of the Keio Medical Society in Tokyo, June 16, 1995.

Reprint requests to: Dr James E Carter, Medical Director, Advanced Surgical Education Associates, Women's Health Center of South Orange County, Inc., 26732 Crown Valley Parkway, Suite 541, Mission Viejo, CA 92691, USA 
section and carefully delineated.

No. 1 Gore-Tex [Gore-tex (Gore Company, Flagstaff, AZ, USA) (2-0 Ethibond can also be used for this procedure - Ethicon, Somerville, NJ, USA)] suture is then introduced through the previously placed $12 \mathrm{~mm}$ port utilizing a contralateral approach to the perivaginal tissue with entry from the left port for suturing on the patient's right perivaginal tissue. The perivaginal tissue is elevated by finger pressure in the vagina and the suture placed $1.5 \mathrm{~cm}$ lateral to the urethrovesical junction (Fig 3 ) and a second passage of the needle through the perivaginal fascia provided for a more secure fastening of this tissue. A Stamey needle is then introduced through a $1.5 \mathrm{~mm}$ incision in the skin just superior to the location of Cooper's ligament as previously dissected (Fig 4). The Stamey needle is then placed between Cooper's ligament

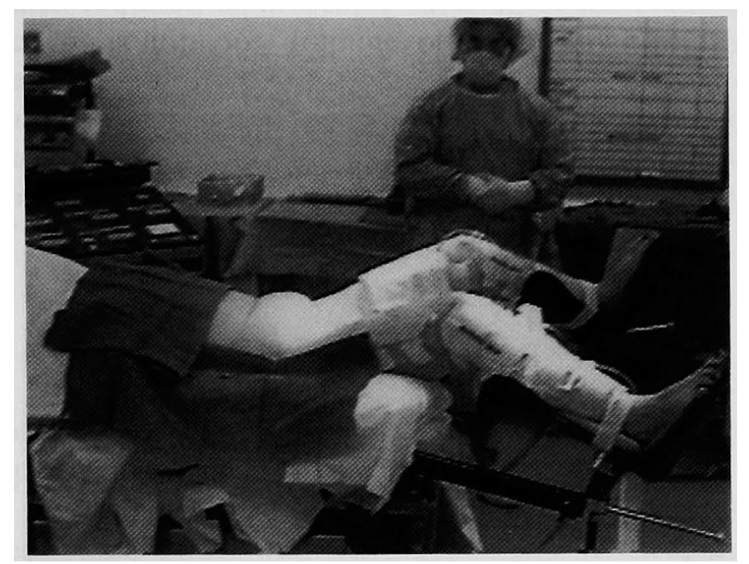

Fig 1 The patient is placed in dorsal horizontal position with appropriate stirrups as shown.

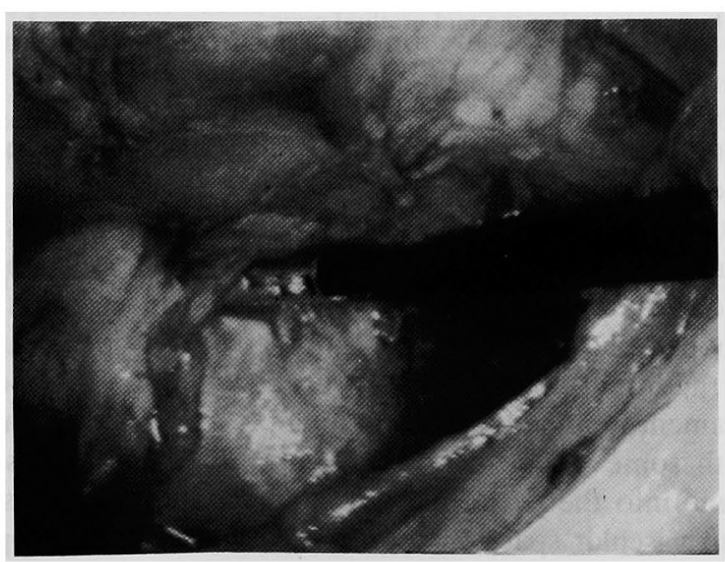

Fig 2 The paravaginal fascia is exposed by sharp and blunt dissection into the space of Retzius. and the bony surface and the Cooper's ligament dissected for a length of 1.0 to $1.5 \mathrm{~cm}$, allowing for a full thickness of $1 \mathrm{~cm}$ of ligament to be exposed (Fig 5). The Stamey needle is exited below the ligament into the cul-de-sac region. The No. 1 Gore-Tex or 2-0 Ethibond is then passed through the eye of the Stamey needle and the Stamey needle then is drawn from its position between Cooper's ligament and the bony surface and then the suture unloaded from the needle (Fig 6). The suture is then withdrawn through its entry port and extracorporeal knotting technique is used to place the knots in the suture, securing the perivaginal fascia to the Cooper's ligament (Fig 7). The same procedure is repeated on the contralateral side. The placement of additional sutures can also be accomplished in the same manner so that two

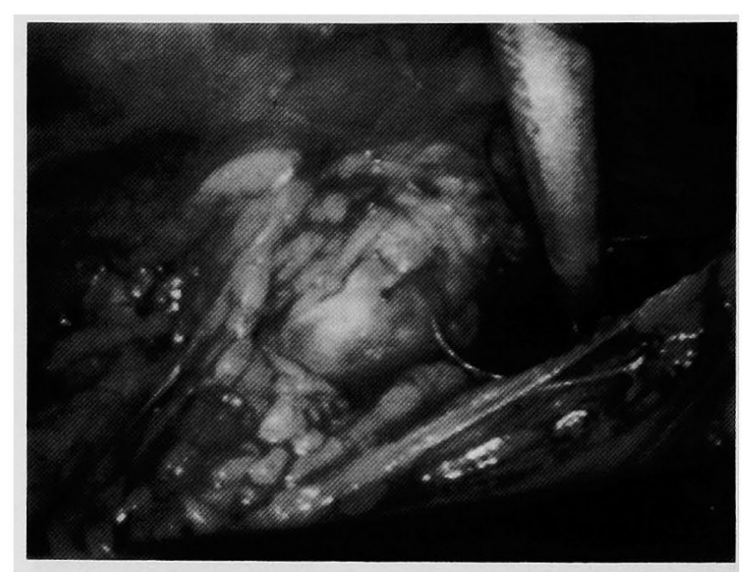

Fig 3 The suture is placed $1-2 \mathrm{~cm}$ laterally to the urethral vesical junction into the paravaginal fascia.

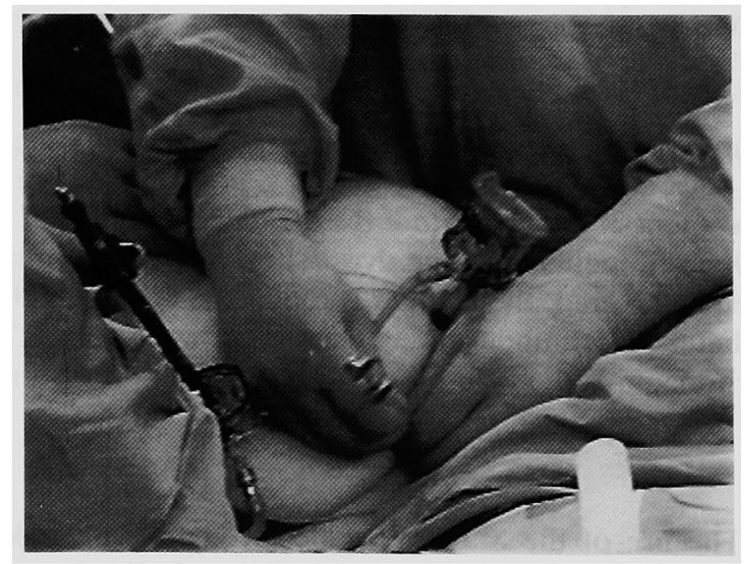

Fig 4 The Stamey needle is inserted at a position approximately $1 \mathrm{~cm}$ superior to the pubic symphysis and at a point approximately $2 / 3$ of the distance between the midline and the pubic rami. 


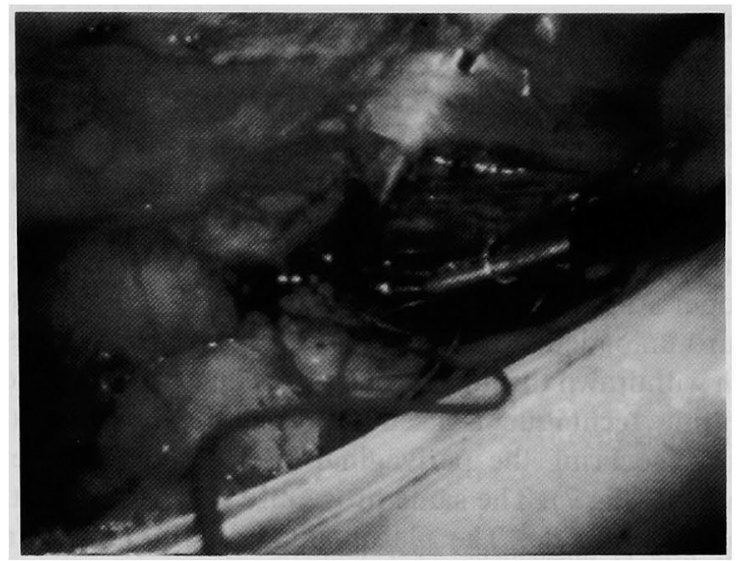

Fig 5 The Stamey needle is passed between the Cooper's ligament and the superior ramus of the pubic bone ensuring a $1 \mathrm{~cm}$ segment of the Cooper's ligament has been obtained.

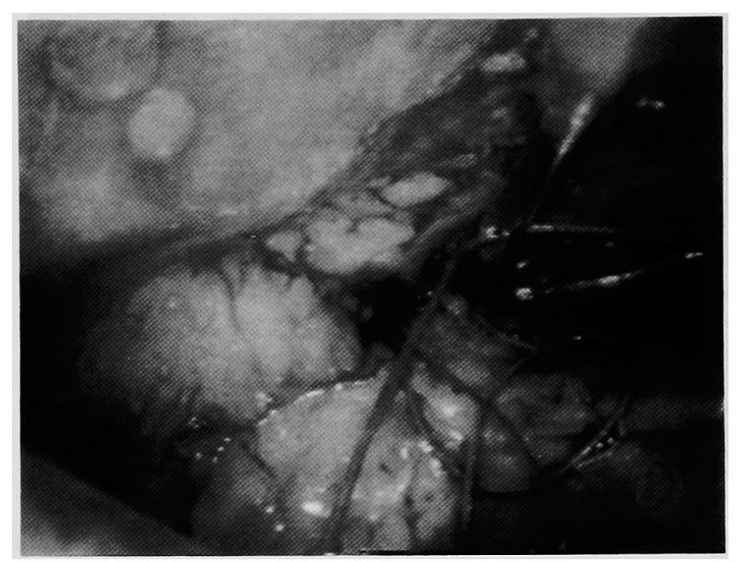

Fig 6 The suture is passed through the eye of the Stamey needle after the tip of the Stamey needle has been passed between the Cooper's ligament and the bone.

sutures on either side of the urethrovesical junction can be placed utilizing this technique (Fig 8). Prior to the placement of the first suture the bladder is emptied of its $350 \mathrm{cc}$ 's of methylene blue dye. After the procedure has been completed, the bladder is refilled and a suprapubic catheter placed under direct view into the bladder. The peritoneum is then closed with use of staples or suture.

\section{Results}

The use of the Stamey needle through a small skin incision just over the region of Cooper's ligament in order to dissect the Cooper's ligament from the bone and make a space for passage of suture between Cooper's ligament and the bony surface replaced the passage of a

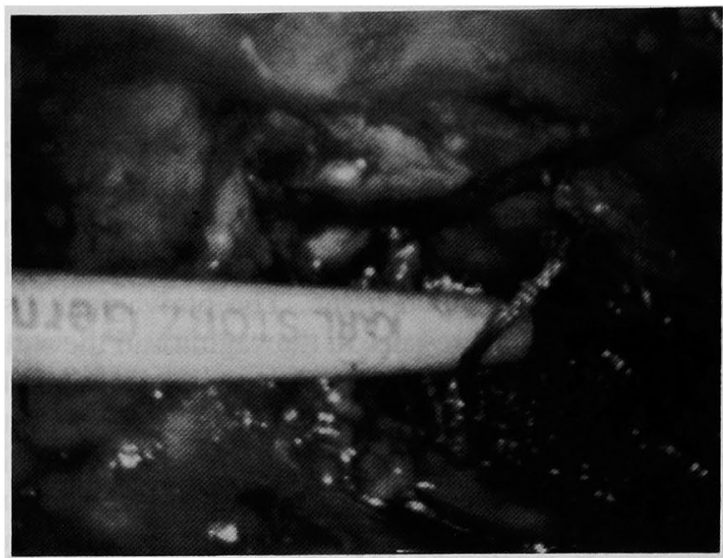

Fig 7 The suture is tied with an extracorporeal knot thus suspending the paravaginal fascia to the Cooper's ligament.

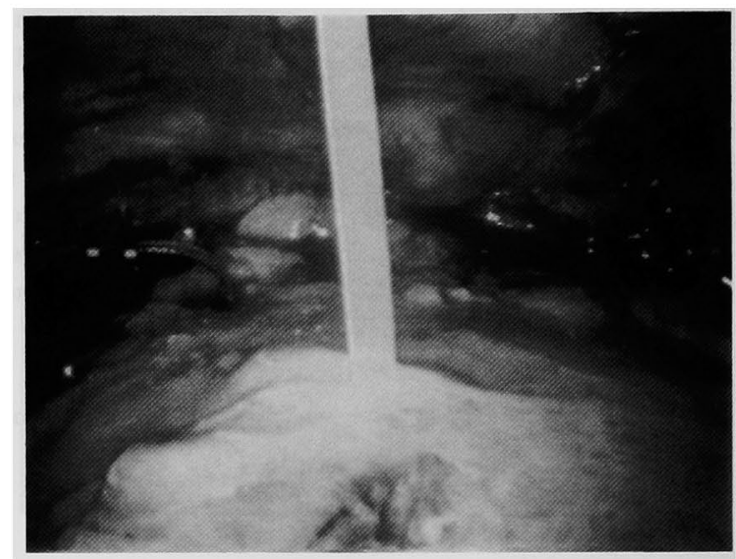

Fig 8 Two sutures are placed on either side of the urethra; one suture on either side approximately $1-2 \mathrm{~cm}$ lateral to the urethra at the urethra-vesical junction and one suture approximately $1-2 \mathrm{~cm}$ lateral to the mid urethral point.

needle through Cooper's ligament. The passage of a needle through Cooper's ligament by laparoscopic approach is a cumbersome procedure which results in variable fixation of the suture to Cooper's ligament because of inability to ensure a uniform segment of Cooper's has been obtained by the suturing procedure. In addition, the suturing procedure to the Cooper's ligament frequently results in multiple attempted passages with some of the passages going into the bone itself, some into the periosteal tissue, and some even passing into vascular spaces. The use of the more blunt-tipped Stamey needle to dissect the Cooper's ligament provides a more uniform thickness of Cooper's ligament for the suspension and avoid sharp-tipped instrumentation against 
the bony surfaces. In addition, the placement of the Stamey needle is a very easily managed surgical procedure under direct laparoscopic vision. The amount of ligament that has been obtained in all cases has been uniformly thick and a full extent of Cooper's ligament has been obtained in all cases attempted.

Fifty cases of laparoscopic Burch procedure utilizing this technique have been performed in the last two years. The patients were released from the hospital within 36 hours after surgery and on average returned to their normal non-strenuous activities within one week of discharge from the hospital. Five patients experienced transient urge incontinence with detrusor instability which required medical therapy for a period of two months and which subsequently resolved. Two patients required long term (three weeks) bladder drainage with the suprapubic catheter due to an inability to void spontaneously. One patient experienced a thermal injury to the bladder which required laparoscopic suturing of the bladder as well as continuous draining of the bladder for three weeks. This thermal injury occurred at the time of dissection of the dome of the bladder from the areolar tissue at the initiation of the procedure. There have been no failures over a period of three years since the initiation of this procedure.

\section{Discussion}

Bladder neck suspension is possible under laparoscopic control. The advantages of laparoscopy now apply to laparoscopic colposuspension.

Since Vancaille's initial report of laparoscopic bladder neck suspension, ${ }^{5}$ Liu has performed over 107 laparoscopic Burch procedures with a complication rate of $10.2 \% .^{7}$ Liu's technique requires the placement of suture into Cooper's ligament with the use of a standard curved needle laparoscopic suturing approach. Smith ${ }^{8}$ described the placement of 300 to $400 \mathrm{cc}$ of methylene blue solution into the bladder to assist with the dissection of the space of Retzius. Davis ${ }^{9}$ described the passage of a Stamey needle through a $5 \mathrm{~mm}$ operating port to pass suture through the perivaginal space and through Cooper's ligament for suspension. The technique described in this paper simplifies the laparoscopic Burch procedure by utilizing the harmonic scalpel for dissection of space of
Retzius in a sharp and blunt fashion, providing for a bloodless dissection of the space, suturing of the perivaginal tissue avoiding penetration of the vaginal mucosa, placing the Stamey needle through a small skin incision, allowing for a variation in the shape of the pelvic bone so that the dissection of Cooper's ligament is performed in a very atraumatic fashion, extracorporeal knotting of the suture for ease of fixation of the perivaginal fascia to the Cooper's ligament and suturing of the peritoneal surface for reclosure of the space using the Carter-Thomason suture passer. ${ }^{10}$

With the adoption of this technique, the procedure of laparoscopic bladder suspension can be performed in most cases in approximately 1 hour of surgical time. The results are very encouraging, and the procedure as described in fact does not differ from the classical Burch procedure in any significant detail. Therefore, the longterm results are expected to be similar to those obtained by the standard Burch approach.

\section{References}

1. Burch JC: Urethrovaginal fixation to Cooper's Ligament for correction of stress incontinence, cystocele, and prolapse. Am J Obstet Gynecol 1961; 81: 281-285

2. Guerinoni A, Treissler A, Klein P: Resultats fonctionnels et urodynamiques de la colpopexie selon Burch. J Gynecol Obstet Biol Reprod 1991; 20: 231-235

3. Eriksen BC, Hagen B, Eik-Nes SH: Long-term effectiveness of the Burch colposuspension in female urinary stress incontinence. Acta Obstet Gynecol Scand 1990; 69: 45-51

4. Marshall VF, Marchetti A, Kranz KE: The correction of stress incontinence by simple vesico-urethral suspension. Surg Gynecol Obstet 1949; 88: 509-515

5. Vancaille TG, Schuessler W: Laparoscopic bladder neck suspension. J Laparoscop Surg 1991; 1: 169-173

6. Carter JE, Bailey TS: Laparoscopic-assisted vaginal hysterectomy utilizing the contact-tip Nd:YAG laser. J Clin Laser Med Surg 1993; 11: 75-77

7. Liu CY, Paek W: Laparoscopic retropubic colposuspension (Burch Procedure). J Am Assoc Gyn Laparoscopists 1993; 1: 31-35

8. Smith ML, ed: Laparoscopic Correction of Urinary Stress Incontinence, Phoenix, Medical Colloquia, Inc., 1992

9. Davis G, Lobell RW: Laparoscopic retropubic colposuspension. The evolution of a new needle procedure. World Congress of Gynecologic Endoscopy Abstracts AAGL, 22nd Annual Meeting, San Francisco, 1993; 5

10. Carter JE: A new technique of fascial ciosure for laparoscopic incisions. J Laparoendoscop Surg 1994; 4: 143-148 